\title{
Use of a Palmaz Intrahepatic Stent for Fixation of a CoreValve During Treatment of Native Aortic Valve Regurgitation
}

\author{
Nirmal Sunkara, $\mathrm{MD}^{1 *}$, Anwar Tandar, MD ${ }^{1}$, Amit N. Patel, MD ${ }^{1,2}$, Mary Hunt Martin, MD ${ }^{1,2}$, \\ Frederick Welt, MD ${ }^{1}$ \\ ${ }^{1}$ Division of Cardiovascular Medicine, University of Utah, Salt Lake City, Utah, USA \\ 2 Primary Children's Hospital, University of Utah, Salt Lake City, Utah, USA
}

\begin{abstract}
Transcatheter aortic valve replacement has been approved and is widely used in the USA for severe calcific aortic stenosis in the high risk inoperable patient. While not approved in patients with native aortic regurgitation (NAVR), there are numerous reports of its use in such patients who are not deemed acceptable surgical candidates. The technical challenges in the NAVR population include lack of fluoroscopic markings due to absence of annular or cusp calcification, increased risk of malpositioning and a risk of residual aortic regurgitation resulting in a high rate (18.8 percent) of need for second valve implantations [1].

Nevertheless, there are numerous reports of TAVR for NAVR. Roy et.al in a registry study of $\mathbf{4 3}$ patients from 14 different countries showed feasibility of CoreValve implantation in extreme operative risk patients with NAVR without aortic stenosis [1]. The implantation of a CoreValve was successful in $97.7 \%$ of cases, however the Valve Academic Research Consortium (VARC)-defined procedural success was only $\mathbf{7 4 . 4 \%}$ due to the need for a second valve.

We submit the first description of using the radial force of a Palmaz biliary stent to affix the upper portion of a CoreValve and mitigate the issue of ventricular migration of the valve in treatment of a NAVR patient with TAVR. We feel this should be considered as an additional tool in the armamentarium of physicians treating this challenging subset of patients.
\end{abstract}

Fax +1 2037853346

E-Mail: jshd@scienceinternational.org

http://structuralheartdisease.org/ (c) 2017 Journal of Structural Heart Disease Published by Science International Corp. ISSN 2326-4004

Accessible online at: http://structuralheartdisease.org/
The Palmaz XL stents are balloon expandable stainless steel prostheses. They have a closed cell design which gives them high radial strength and are designed for an expansion range of $10 \mathrm{~mm}-25 \mathrm{~mm}$ while maintaining their radial strength of $12 \mathrm{psi}$. Their foreshortening ranges between $2.5 \%$ at $10 \mathrm{~mm}$ and $23 \%$ at $25 \mathrm{~mm}$ [4]. This foreshortening has to be taken into account when adjusting the overlap portion when using as described above with the CoreValve.

Copyright @ 2017 Science International Corp.

\section{Key Words}

Aortic regurgitation • TAVR • Core valve • Palmaz stent

\section{Introduction}

Transcatheter aortic valve replacement (TAVR) has been approved and is widely used in the United States for severe calcific aortic stenosis in high-risk inoperable patients. Although not approved for patients with native aortic regurgitation (NAVR), there are several reports of its use in such patients who are not deemed acceptable surgical candidates. Patients with NAVR pose numerous technical challenges. The absence of annular or cusp calcification in NAVR means a lack of fluoroscopic markings, which can make valve positioning more challenging. The lack of

\section{* Corresponding Author:}

Nirmal T. Sunkara, MD

Division of Cardiovascular Medicine

University of Utah

30 N 1900 E, \#4A100, Salt Lake City, UT 84101, USA

Tel. +1 657333 2079, Fax: +1 888433 9843, E-Mail: nirmalsunkara@gmail.com 
a calcified substrate also increases the risk of malpositioning. Furthermore, there is a risk of residual aortic regurgitation, resulting in a high rate $(18.8 \%)$ of need for second valve implantations [1].

Nevertheless, several reports have described the use of TAVR in patients with NAVR. In a registry study of 43 patients from 14 different countries, Roy et al. demonstrated the feasibility of CoreValve implantation in extreme operative risk patients with NAVR without aortic stenosis [1]. The implantation of a CoreValve was successful in $97.7 \%$ of cases; however, the Valve Academic Research Consortium-defined procedural success rate was only $74.4 \%$ due to the need for a second valve in some cases. The Italian CoreValve multicenter registry confirmed its feasibility in 26 patients and showed that patients with NAVR are usually younger than those undergoing TAVR for aortic stenosis [2]. In this report, we describe a challenging case of implanting a CoreValve for NAVR and a reproducible solution.

\section{Case Presentation}

The patient was a 38-year-old male with pulmonary valve dysplasia associated with Noonan's syndrome and hypertrophic cardiomyopathy. The patient underwent pulmonary valvotomy and myomectomy at 17 months of age followed by a pulmonary homograft for severe pulmonary insufficiency at 20 years of age. With a history of multiple episodes of infective endocarditis on the aortic valve, he subsequently developed severe aortic insufficiency and was referred to us for possible TAVR. Due to significant frailty, poor pulmonary function, and prior sternotomies, he was considered a candidate for TAVR. His STS score for mortality or morbidity was calculated as $24.83 \%$.

Computed tomography (CT) measurements suggested a minimum annulus diameter of $23.3 \mathrm{~mm}$ and a maximum annulus diameter of $30.1 \mathrm{~mm}$. The perimeter of the annulus was measured on CT images as $88 \mathrm{~mm}$, and the area was calculated as $596.2 \mathrm{~mm}^{2}$ (Figure 1). No calcification was noted in the annulus. Plans were made for implantation of a 31-mm CoreValve (Medtronic, Minneapolis, MN, USA).

The procedure was completed under general anesthesia. Transesophageal echo image guidance was used throughout the procedure. Bilateral femoral

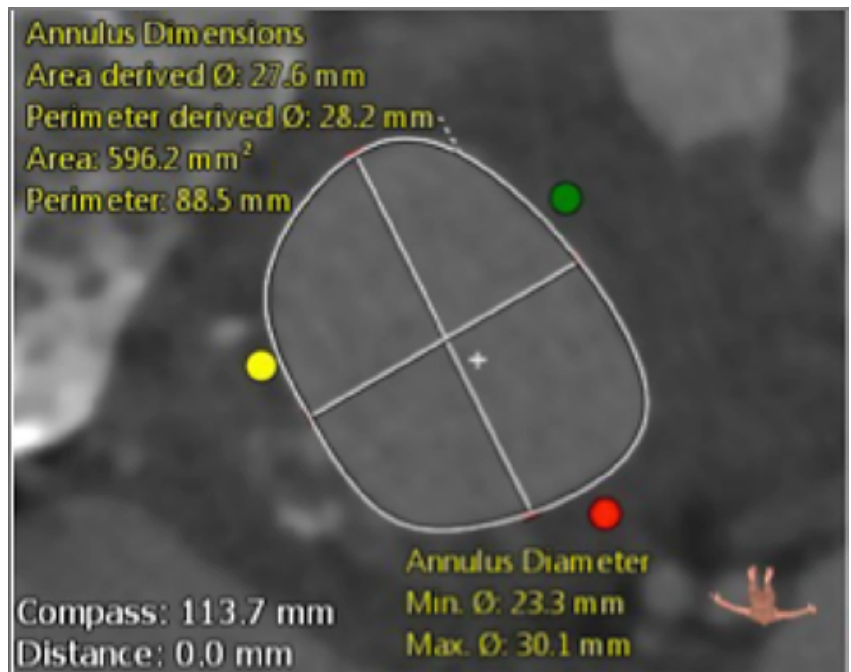

Figure 1. Aortic annulus measurements pre procedure using 3 mensio showed a annulus perimeter of $88 \mathrm{~mm}$ and a maximum diameter of $30.1 \mathrm{~mm}$ and a minimum diameter of $23.3 \mathrm{~mm}$.

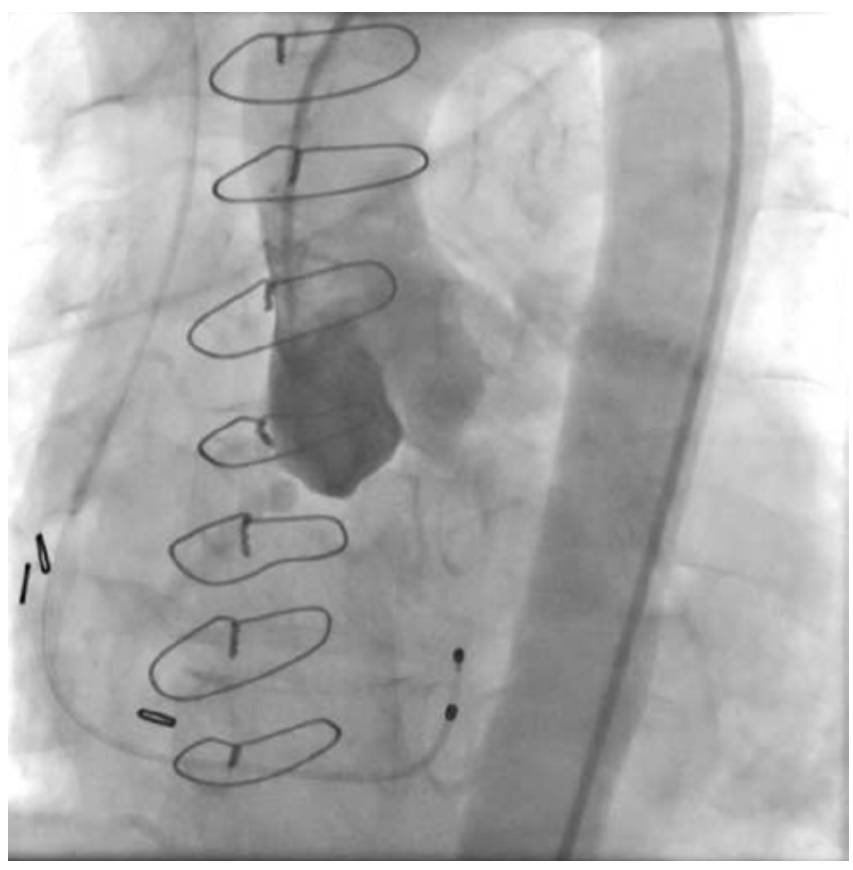

Figure 2. A 6-F pigtail catheter in the right coronary cusp.

artery access was obtained using a micropuncture needle and the modified Seldinger technique. A 6-F arterial sheath was placed in the left femoral artery, and a 6-F pigtail catheter was advanced over a $0.035 \mathrm{~J}$ wire and positioned in the right coronary aortic cusp (Figure 2). A 28-cm 18-F Gore dryseal sheath (Gore Medical, Flagstaff, AZ, USA) was placed in the right femoral artery. A double curve Lunderquist extra stiff 


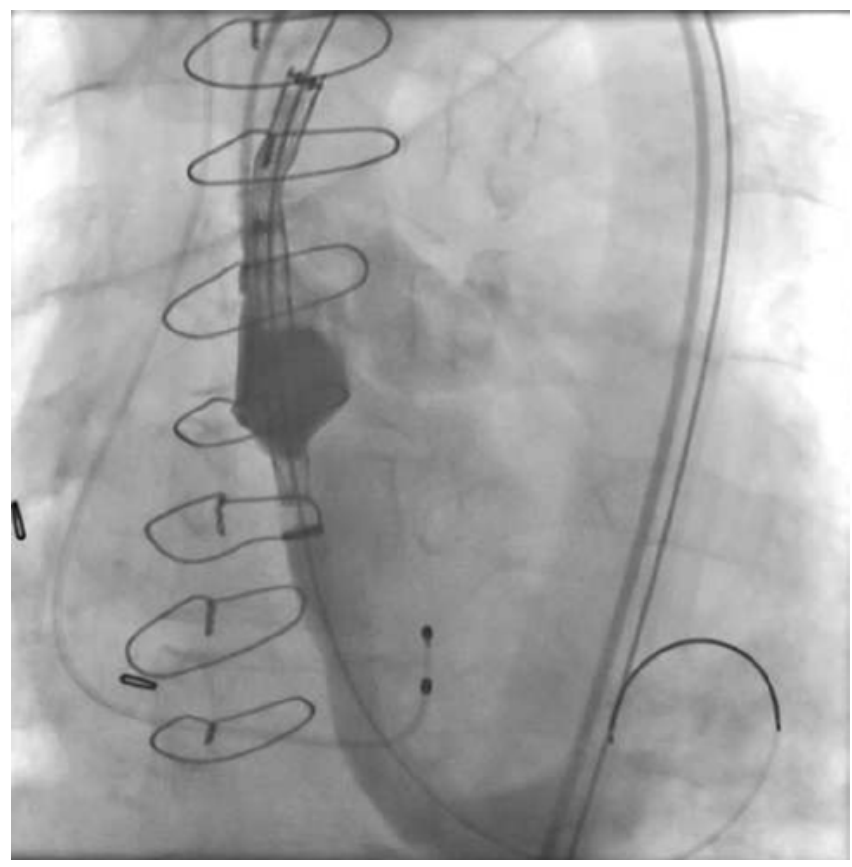

Figure 3. Appropriate positioning of the CoreValve predeployment.

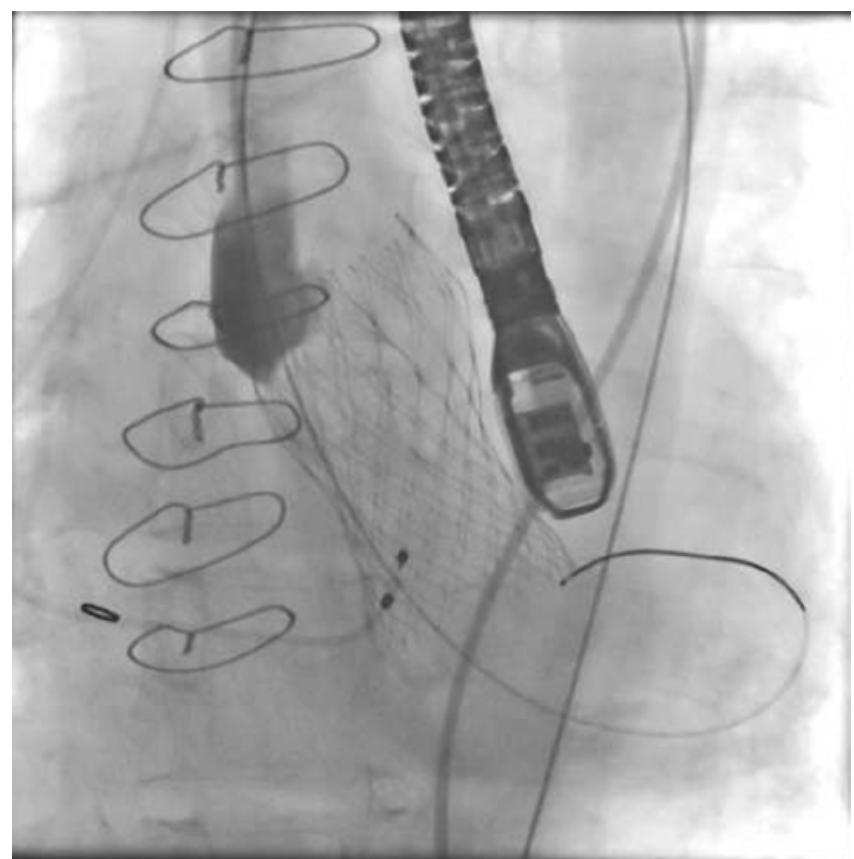

Figure 4. Deformation of the proximal struts of CoreValve suggesting external impingement. Ventricular displacement of the Corevalve is seen.

wire (Cook Medical, Bloomington, IN, USA) was positioned in the left ventricle to facilitate the CoreValve implantation.

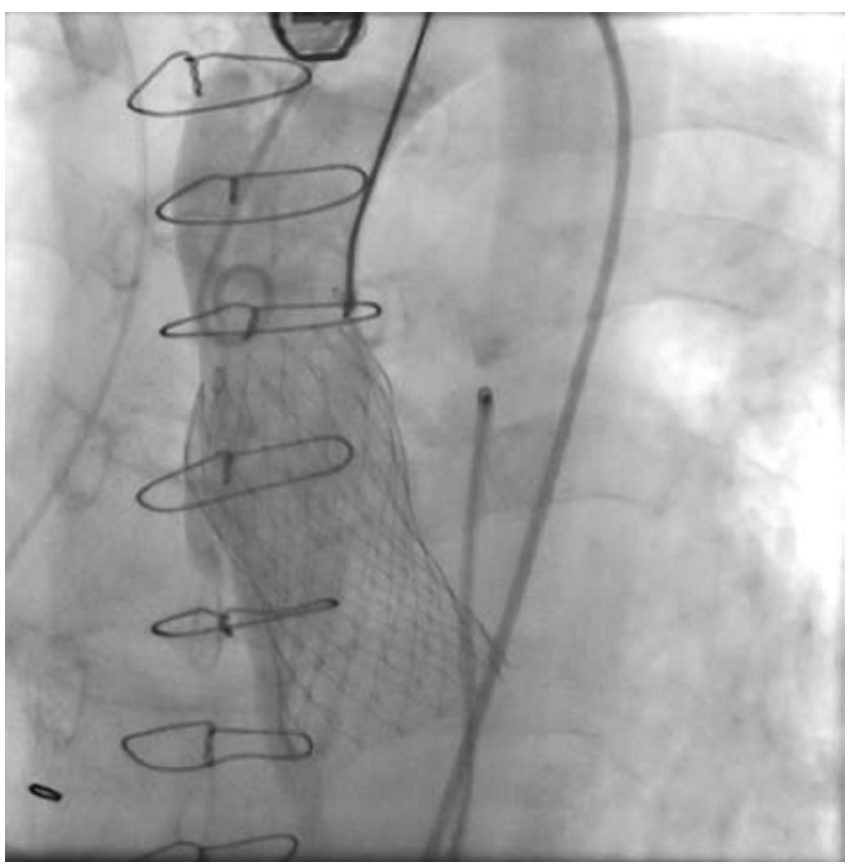

Figure 5. Left tab of the CoreValve snared with a 25-mm Amplatz GooseNeck snare and valve pulled into proper position. Note abluminal projection of the proximal struts.

A 31-mm CoreValve was prepped, and its orientation was confirmed. The valve was advanced across the aortic valve, confirming its position in the right coronary cusp using the pigtail catheter in coplanar view under fluoroscopy, and deployed under rapid pacing at $130 \mathrm{bpm}$. After valve deployment and release, it was noted to be functioning well initially but with impingement on the valve at the greater curvature of the aorta, which was thought to possibly be secondary to pulmonary artery enlargement (Figure 3). Subsequently, the valve migrated toward the ventricle in an unacceptably low position (Figure 3). Left radial arterial access was obtained, and a $120-\mathrm{cm} 6-\mathrm{F}$ GooseNeck snare (ev3, Amplatz, Plymouth, MN, USA), was advanced into the ascending aorta. The left tab of the valve oriented toward the lesser curvature of the aorta was snared with the $25-\mathrm{mm}$ snare, and the valve was pulled cephalad into an appropriate position. However, with release of tension on the snare, the valve migrated toward the ventricle, which was thought to be due to impingement on the greater curvature of the aorta (Figure 4). CT measurements of the aorta at this level of impingement were approximately $23 \mathrm{~mm} \times 20 \mathrm{~mm}$. 

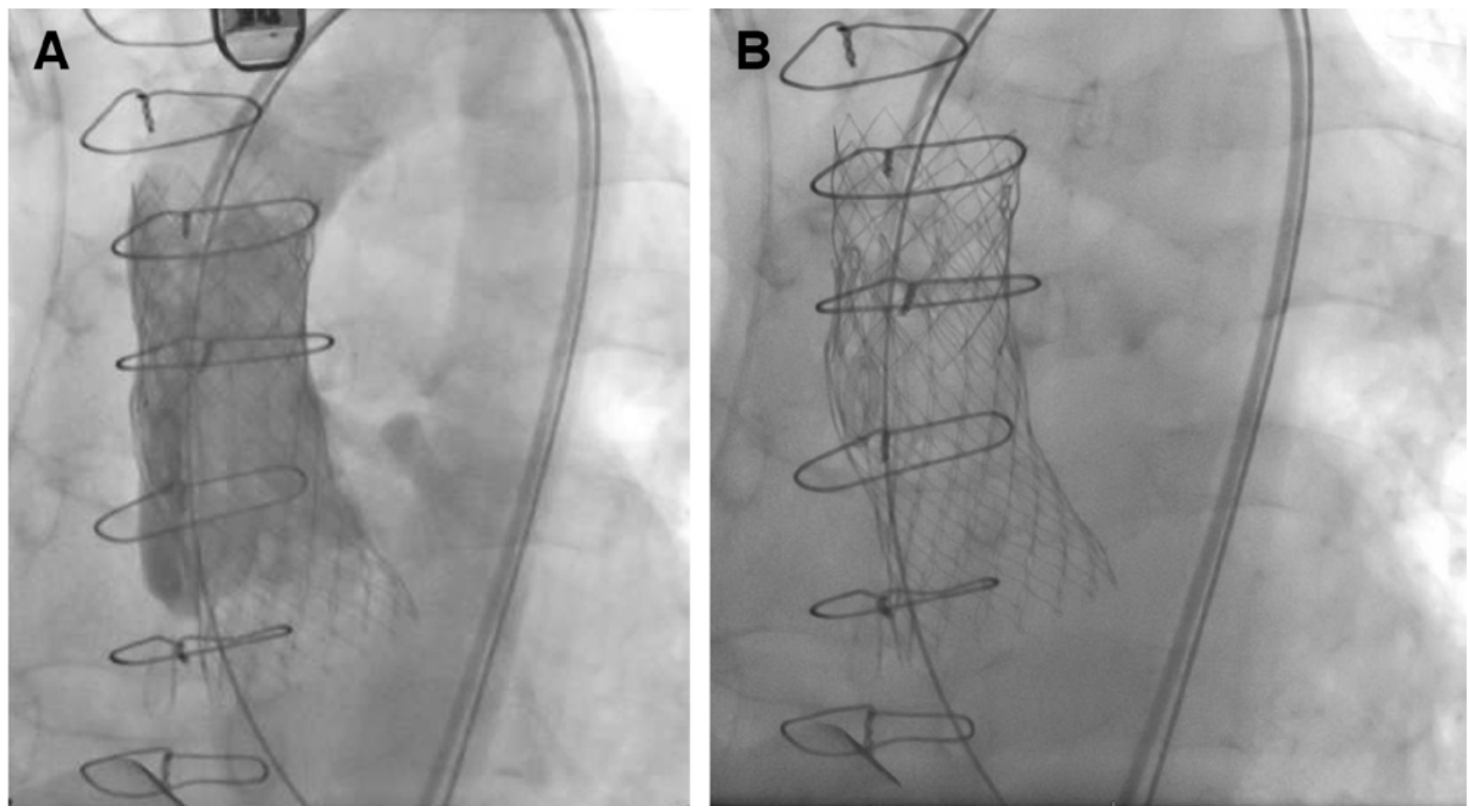

Figure 6. Panel A. CoreValve in appropriate position and patent coronary arteries with mild paravalvular leak noted on final aortogram. Panel B. CoreValve in appropriate position with the Palmaz XL deployed fixing the upper portion of the CoreValve.

To maintain the position of the valve, a Palmaz $\mathrm{XL}$ transhepatic biliary stent $(40 \mathrm{~mm}$ unexpanded length $\times 10 \mathrm{~mm}$ expansion diameter; Cordis Corp., Rancho Cordova, CA, USA) was placed to achieve adequate radial force against the impingement. This Palmaz stent was then crimped onto a 24-mm balloon in balloon (BIB) catheter (inner: $12 \mathrm{~mm}$ diameter $\times 3 \mathrm{~cm}$ length, outer: $24-\mathrm{mm}$ diameter $\times 4$-cm length; NuMED Inc, Hopkinton, NY, USA). The outer balloon was then slightly inflated to prevent the Palmaz stent from sliding off the balloon. A 75-cm 12-F Check-Flo introducer sheath (Cook Medical, Bloomington, IN, USA) was used to advance the BIB balloon-mounted crimped Palmaz stent into the ascending aorta. The Check-Flo introducer sheath was then withdrawn, leaving the BIB balloon-mounted Palmaz stent in place overlapping the proximal stent end of the CoreValve. Rapid pacing at $180 \mathrm{bpm}$ was initiated, and the inner and outer balloons were inflated in succession, securing the stent and valve in place, and the GooseNeck snare was released (Figure 5). The BIB balloon was then fully inflated to position the Palmaz stent, which appeared to fix the CoreValve in place. Post-procedure aortogram confirmed acceptable location of the valve, pa- tency of the coronary arteries, and mild paravalvular leak (Figure 6). The patient was extubated immediately and monitored overnight in the intensive care unit. He felt symptomatically improved and was discharged home next day.

The patient showed a significant reduction in shortness of breath two weeks post-procedure and at 1-month follow-up. Echocardiographic evaluation at 2 and 6 months confirmed accurate positioning of the valve with good valve function (Figure 7A and 7B). However, we also noted moderate perivalvular regurgitation, highlighting difficulty in treating NAVR with TAVR. Furthermore, the 6-month follow-up echocardiogram revealed a moderate to severe paravalvular leak, and the patient exhibited increased fatigue and failure to thrive. After discussion, we decided to proceed with placing a valve-in-valve transcatheter using an overexpanded Sapien S3.

\section{Discussion}

This is the first description of the use of the radial force of a Palmaz biliary stent to affix the upper portion of a CoreValve and mitigate the ventricular mi- 


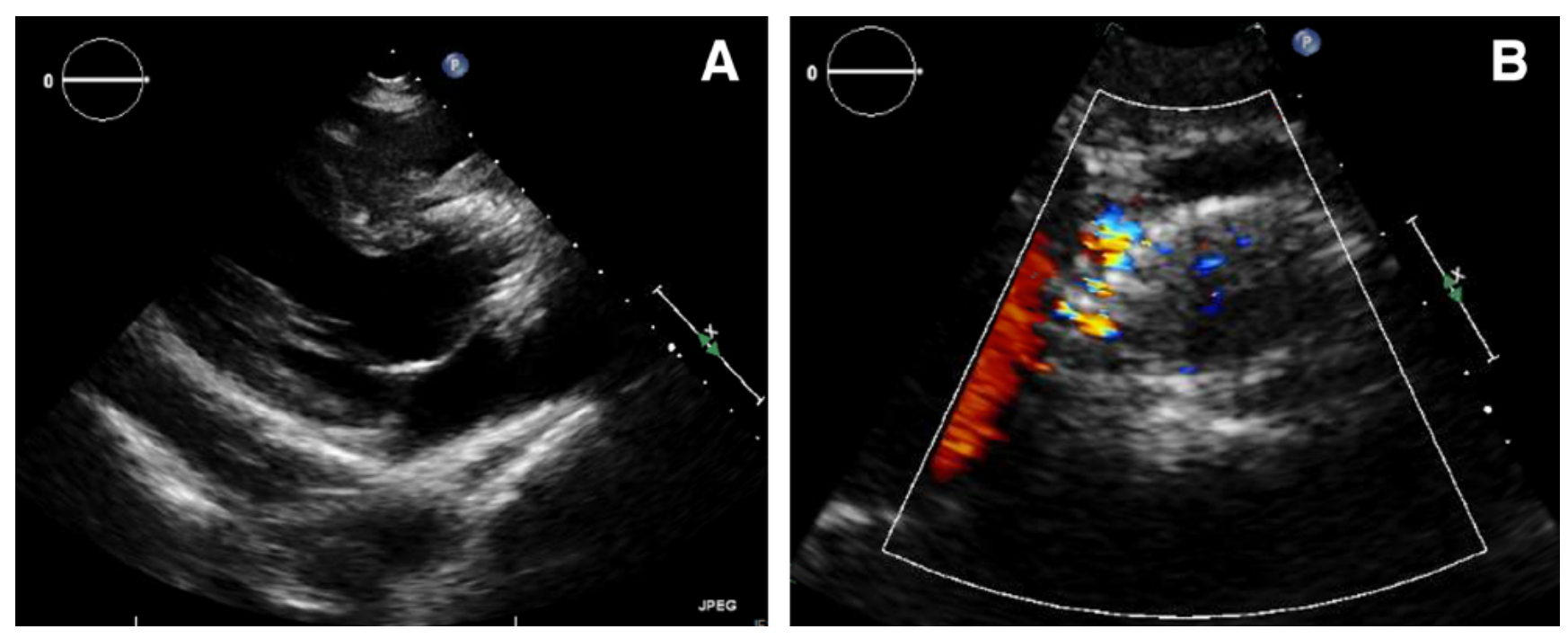

Figure 7. Panel A. Six-month follow-up transesophageal echocardiogram shows adequate positioning of the CoreValve in a parasternal long axis view. Panel B. Transesophageal echocardiogram short axis view of aortic valve showing turbulent flow suggestive of perivalvular leak.

gration of the valve in treating a NAVR patient with TAVR. We believe that this should be considered as a possible approach to treatment in this challenging subset of patients.

The CoreValve system consists of a self-expandable, tri-level frame made of nitinol attached to a tri-leaflet porcine pericardium heart valve. Most reports of TAVR for NAVR have utilized the CoreValve for its unique self-expanding properties. The upper third/outflow portion of the frame exerts low radial force and sits within the ascending aorta, functioning to orient the prosthesis in the direction of the aortic root and blood flow. The middle third of the frame is constrained to avoid jailing of the coronary arteries and hosts the valve leaflets. It has high hoop force to resist deformation and thus maintain normal leaflet function. The lower third/inflow portion of the frame sits within the left ventricular outflow tract/annulus of the native aortic valve and exerts high radial force. Thus, the prosthesis is anchored within the annulus, and its function is supra-annular [3, 4]. In our case, we required additional stabilization at the upper third/ outflow portion of the valve, which was adequately provided by the Palmaz stent.

Palmaz stents are balloon-expandable stainless steel prostheses. All Palmaz stents have a closed cell design, which gives them high radial strength and makes them useful for treating coarctation of the aor- ta. Most Palmaz stents must be hand-crimped onto a balloon (for example, the 3010 is available mounted on a 12-mm delivery balloon). In the Palmaz stent nomenclature, first two digits indicate the unexpanded stent length, and the last one or two digits indicate the minimum recommended expansion diameter. Large Palmaz stents (P308) have a recommended expansion diameter between $8-12 \mathrm{~mm}$, with reported overdilation to $18-20 \mathrm{~mm}$. Overdilation of these stents leads to significant foreshortening $<33 \%$ at 12 $\mathrm{mm}$ and up to $50 \%$ at $18 \mathrm{~mm}$ and decreases radial strength. Palmaz XL transhepatic stents are designed for an expansion range of 10-25 mm while maintaining a radial strength of 12 psi (comparative radial strength of the large Palmaz P308 stent is 6 psi). Their foreshortening ranges between $2.5 \%$ at $10 \mathrm{~mm}$ and $23 \%$ at $25 \mathrm{~mm} 10-13$. In our situation, based on measurements of the ascending aorta and the root, both on CT prior to the procedure and aortogram during the procedure, we required a stent expanded to 23 $\mathrm{mm}$. This required the use of a Palmaz XL transhepatic stent and a 1:1-sized balloon. The foreshortening of the Palmaz stent must be taken into account when determining the length of the stent to ensure adequate overlap with the CoreValve and to prevent jailing of the origin of the innominate and left carotid and subclavian arteries. We used a P4010 stent, accounting for foreshortening and the distance from 
the origin of the innominate artery, to avoid jailing of this artery.

When choosing a balloon, diameter and length are important considerations. Shorter balloons offer the advantage of inflating the inner part of the stent first, thus avoiding the potential complication of flaring of the ends of the stents, resulting in balloon rupture or vessel wall perforation; however, this can result in stent sliding or embolization. Longer balloons allow more precise placement and repositioning if necessary before their full inflation. The BIB balloon has two balloons, one shorter (inner) and one longer (outer) than the stent, which offers potential advantages. In our situation, to prevent the crimped Palmaz stent from sliding off the balloon during its introduction into the sheath, we inflated the inner balloon to a low $2 \mathrm{~atm}$. Once the sheath is withdrawn and the stent is adequately positioned, the inner balloon is inflated first. After the position of the inner balloon is ensured to be satisfactory, the outer balloon is inflated. In choosing the diameter of the balloon, we took into consideration the measurements of the ascending aorta based on pre-procedure CT and aortogram performed during the procedure. The balloon was sized 1:1 with the intent to expand the Palmaz stent and adequately fix the CoreValve in place.

Potential risks of this approach that should be kept in mind are vessel wall perforation while deploying the Palmaz stent, balloon rupture and aortic dissection, inadequate expansion of the Palmaz stent with ventricular migration of the stent and valve, and possible jailing of the major branches of aorta. Careful measurements of the ascending aorta and balloon and stent sizing, taking foreshortening into account, should minimize such complications.

There are a variety of other valves in various stages of development that are designed for the treatment of NAVR. These typically utilize a transapical approach and include the Acurate TA valve, Medtronic engager valve, and Jena valve [5-8]. The Helio transcatheter dock (Edwards Lifesciences, Irvine, CA, USA) has been described as an ancillary device intended to confer greater annular stability to the Edwards SAPIEN XT valve. The dock consists of a self-expandable nitinol stent with a polyethylene skirt designed to be positioned inside the aortic root, which is intended to secure the balloon-expandable SAPIEN XT by incorporating and entrapping the native cusps [9].

TAVR is not an approved treatment for NAVR, although it is being used off-label in high-risk surgical candidates. Experience in using the transcatheter approach to treat NAVR is limited but growing. Patients with mixed aortic valve disease with severe stenosis and at least moderate regurgitation have been successfully treated with both commercially available TAVR devices, but NAVR without stenosis is still considered a relative contraindication in published guidelines.

Newer-generation valve designs that use leaflet pinning or stabilization mechanisms are showing promise, but experience with these devices is still limited. Therefore, additional experience and evidence from larger registries, longer follow-up periods, and randomized clinical trials is necessary for the expanded use of TAVR for NAVR.

\section{Conflict of Interest}

Dr. Welt has reported as being on the advisory board for Medtronic.

\section{Comment on this Article or Ask a Question}

\section{References}

1. Roy DA, Schaefer U, Guetta V, Hildick-Smith D, Möllmann H, Dumonteil N, et al. Transcatheter aortic valve implantation for pure severe native aortic valve regurgitation. J Am Coll Cardiol. 2013;61:1577-1584. DOI: 10.1016/j.jacc.2013.01.018

2. Testa L, Latib A, Rossi ML, De Marco F, De Carlo M, Fiorina $C$, et al. CoreValve implantation for severe aortic regurgitation: a multicentre registry. Eurolnterven- tion. 2014;10:739-745. DOI: 10.4244/EIJV1016A127

3. Piazza N, de Jaegere P, Schultz C, Becker $A E$, Serruys PW, Anderson RH. Anatomy of the aortic valvar complex and its implications for transcatheter implantation of the aortic valve. Circ Cardiovasc Interv. 2008;1:74-81. DOI: $10.1161 / C I R C I N T E R-$ VENTIONS.108.780858

4. Adams DH, Popma JJ, Reardon MJ. Tran- scatheter aortic-valve replacement with a self-expanding prosthesis. N Engl J Med. 2014;371:1790-1798. DOI: 10.1056/NEJMc1408396

5. Seiffert $M$, Diemert $P$, Koschyk $D$, Schirmer J, Conradi L, Schnabel R, et al. Transapical implantation of a second-generation transcatheter heart valve in patients with noncalcified aortic regurgitation. JACC Cardiovasc Interv. 2013;6:590-597. DOI: 10.1016/j. 
jcin.2013.01.138

6. Kiefer P, Seeburger J, Mohr FW, Holzhey DM. Transcatheter aortic valve replacement for isolated aortic valve insufficiency: experience with the Engager valve. J Thorac Cardiovasc Surg. 2014;147:e37-e38. DOI: 10.1016/j.jtcvs.2013.11.035

7. Sündermann SH, Holzhey D, Bleiziffer S, Treede $H$, Jacobs $S$, Falk V. Second-generation transapical valves: the Medtronic Engager system. Multimed Man Cardiothorac Surg. 2014;mmu001. DOI: 10.1093/mmcts/ mmu001

8. Wendt D, Kahlert P, Pasa S, El-Chilali K, Al-Rashid F, Tsagakis K, et al. Transapical transcatheter aortic valve for severe aortic regurgitation: expanding the limits. JACC Cardiovasc Interv. 2014;7:1159-1167. DOI: 10.1016/j.jcin.2014.04.016
9. Barbanti M, Ye J, Pasupati S, El-Gamel A, Webb JG. The Helio transcatheter aortic dock for patients with aortic regurgitation. Eurolntervention. 2013;9 Suppl:S91-S94. DOI: 10.4244/EIJV9SSA17

10. Ebeid M. Balloon expandable stents for coarctation of the aorta: review of current status and technical considerations. Images Paediatr Cardiol. 2003;5:25-41. PMCID: PMC3232539

11. Peters B, Ewert P, Berger F. The role of stents in the treatment of congenital heart disease: Current status and future perspectives. Ann Pediatr Cardiol. 2009;2:3-23. DOI: 10.4103/0974-2069.52802

12. Forbes TJ, Gowda ST. Intravascular stent therapy for coarctation of the aorta. Methodist Debakey Cardiovasc J. 2014;10:82-87. PMID: 25114759
13. Montague BJ, Kakimoto WM, Arepally A, Razavi M, Dake MD, Hofmann, LV. Response of balloon-expandable endoprosthetic metallic stents subjected to over-expansion in vitro. Cardiovasc Intervent Radiol. 2004;27:158-163. DOI: 10.1007/ s00270-003-4600-y

Cite this article as: Sunkara $\mathrm{N}$, Tandar A, Patel AN, Martin MH, Welt F. Use of a Palmaz Intrahepatic Stent for Fixation of a CoreValve During Treatment of Native Aortic Valve Regurgitation. Structural Heart Disease. 2017;3(1):28-34. DOI: http://dx.doi. org/10.12945/j.jshd.2017.16.007 